\title{
The Impact of the Three Gorges Hydroelectric Project on and the Preservation Strategies for the Biodiversity in the Affected Region
}

\author{
HE JINSHENG XIE ZONGQIANG \\ Institute of Botany, Academia Sinica, Beijing 100044, China \\ (Received February 14, 1995)
}

\section{ABSTRACT}

The impact of the Three Gorges Hydroelectric Project on the plant diversity in the reservoir region was assessed based upon field surveys of the plant species and vegetation surrounding the reservoir area that will be influenced by this project. The reservoir area harbors known higher plants (except Bryophytes) of 190 families. 1012 genera, 3012 species (including 29 sub-species. 286 varieties and 16 forms). Of which, 37 endemic species can only be found in the reservoir region, 47 species, including 22 endangered species, 20 rare species and 5 threatened species, have been listed in the "Plant Red Data Book of China". Vegetation types in the reservoir area, except for those found in the cultivated land, have 89 formations. The coniferous forests are most widely distributed. while broadleaf evergreen forests are only scattered in the central parts of the mountain. The plants belonging to 120 families, 358 genera and 550 species that are at present distributed under the flooded line $(185 \mathrm{~m})$ in the reservoir will be affected by the project, based on their current distributional range from the established database. Moreover. 27 community types in the potentially flooded area will be eliminated from the area as well. since the original habitats of some species will be destroyed after the reservoir is filled with water. Flooding will directly lead to the extinction of species and community types in the reservoir region unless preservation strategies are to be taken. Even if it is assessed solely based on the loss of natural vegetation and the destruction of the habitats that are currently cultivated, the economic loss caused by flooding will be severe.

Key words biological diversity, Three Gorges Hydroelectric Project, preserving strategies, impact of the hydroelectric project

\section{Introduction}

On April 3, 1992, the People's Congress of China finally passed a bill on the construction of the Three Gorges Hydroelectric Project. This project was planned as part of economic and social development program to be implemented during the next 10-Year Plan. Therefore, the evaluation studies on building the Three Gorges dam was finally completed, and the biggest hydroelectric project in the history of China came to an operation stage. The Three Gorges dam project has won a world-wide attention since its initial stage. For instance, many international organizations and internationally-known experts were involved in the proposal preparation. site investigation and the final evaluation of this project. Various institutions and organizations carried out detailed studies 
and gathered a certain amount of information (Jin et al, 1983; Jin et al, 1984; Chen, 1991). The Chinese Academy of Sciences (CAS), on behalf of the State Science and Technology Commission of China, coordinated a project entitled "Study on Impact of the Three Gorges Hydroelectric Project on Ecological Environment and the Possible Strategies for Action". This study lasted for 5 years. The first phase of this study was to answer whether the dam would benefic the environment. The second phase was to gather fundamental background information and to look for long-term strategies as regard to the sustainable development and conservation of the Yangtze River region and its environments. In terms of terrestrial plant conservation, the purpose of the study reported in this paper was disigned to look for ways by which the natural and man-managed vegetation, species diversity and endangered plants could be conserved.

The Three Gorges region is rich in plant species diversity, since this area was merely affected by the Quaternary Glacier. Therefore, many relic plants are kept here, along with many endemic plant species and genera (Zheng, 1984; Ying et al., 1984). Since the early 1880s, this area has received wide attention of the Chinese and foreign botanists. Henry, A (1885 1888); Wilson E H (1900, 1907, 1909), Faber E (1887) and Silvestri $R \quad(1904 \sim 1907)$ and some famous Chinese botanists came here to collect plant specimens (Bretschneider, 1962).

This paper is to discuss the results of a detailed survey of the plant species diversity, community types along the Yangtze River, to identify the region's higher plant species, vegetation types, and to evaluate the impact of this project on species diversity and vegetation types.

\section{The natural environmental conditions in the reservoir region}

The reservoir region includes the 19 counties and cities that will be affected by the project. This region is located at the longitude of $\mathrm{E} 106^{\circ} \sim 111^{\circ} 50^{\prime}$, latitude of $\mathrm{N} 29^{\circ} 16^{\prime}$ $\sim 31^{\circ} 25^{\prime}$, the eastern end is Yichang City of Hubei Province and the western end is Baixian of Sichuan Province (Figure 1).

The Yangtze River rises in rugged mountains on the northern border of Tibet. It flows 6300 kilometers eastward to enter the Pacific Ocear in Shanghai. Situated on about two-thirds of the way to Shanghai is a spectacular stretch, 200 kilometers long. called the Three Gorges. There the river bisects three mountain ranges. The south of the reservoir is Wushan mountain and Qiyaoshan mountain with an altitude of 1000 $1500 \mathrm{~m}$. The north of the reservoir is Daba mountain. The central reservoir is paralleled terraces and forms paralleled valleys of eastern Sichuan. Wold, hill terrace and plain cover $67.7 \%$. 29. $5 \%$ and $0.9 \%$, respectively, of the total reservoir area (Chen, G, 1991). The climate of reservoir area is characterized by warm winter and dry spring. hot and dry summer, abundant precipitation in autumn, high humidity and foggy weather. which is typical of the humid subtropical monsoon type. The annual mean temperature is $15 \sim 19^{\circ} \mathrm{C}$, and the annual precipitation ranges from $1000 \sim 1200 \mathrm{~mm}$. The rainfall from April to October occupies over $80 \%$ of the annual precipitation, and hot summer occurs from July to August.

Main soil types of the reservoir region are yellow soil, red loam, yellow brown soil, brown rendzima, black rendzima, rice soil and alluvial soil. Some brown soil, dark 


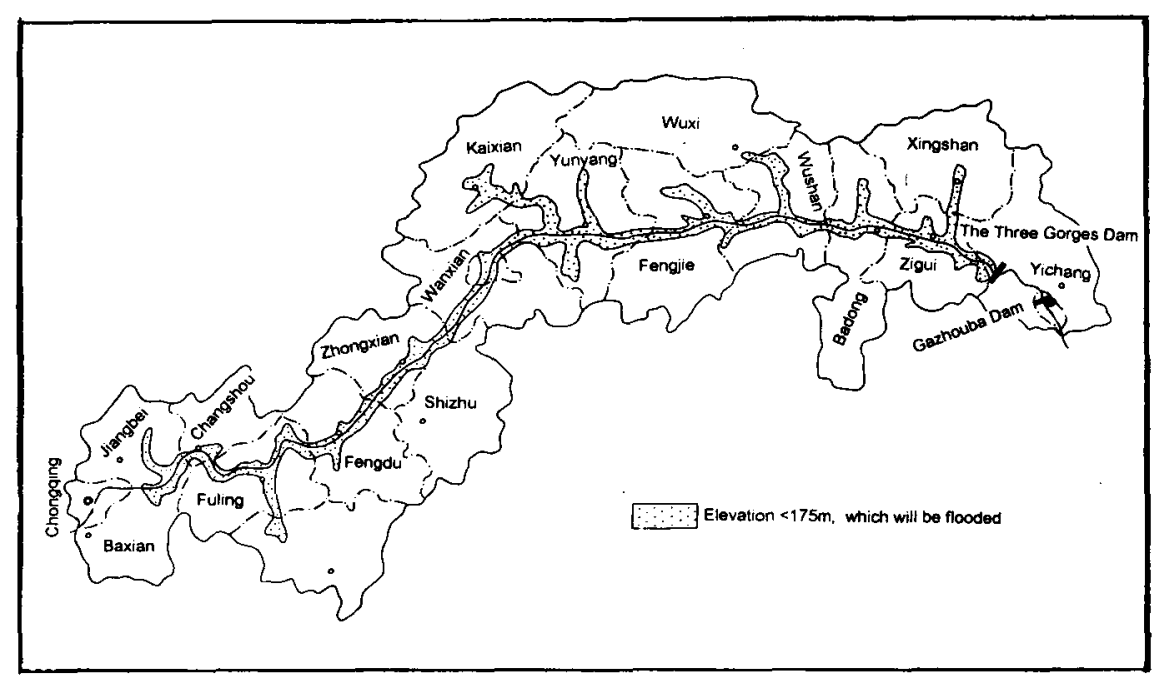

Fig. 1 The map of the Three Gorges Reservoir region.

brown and mountain soil types exist at higher elevation of the mountains.

The region lies in the northern part of the sub-tropical zone, and has mild climate and abundant rainfall. All the climatic features are suitable for many plants to grow. Since the Quaternary Glacier had a little impact on the flora of the Three Gorges region, this area became a refuge for plants in the Tertiary period, keeping many relic plants and endemic species (Zheng, 1984; Ying et al., 1984). Therefore, the Three Gorges region is one of the key areas for biodiversity conservation (Chen, L., 1993).

The long history of human activities and natural disaster has a significant influence on the region, especially the rapid expansion of population. The natural vegetation has been severely damaged and serious soil erosion has taken place. At present, the forest coverage is only $19.5 \%$ (closed canopy forest $14.9 \%$ ) in the reservoir, therefore, the Three Gorges region is also an area with severely degraded ecosystems.

\section{Methods of study}

From 1984 1990, Institute of Botany, Wuhan Institute of Botany, Chendu Institute of Biology of the CAS undertook a series of studies on plant species and community diversity in the reservoir region. The research contributed greatly to the basic understanding of the plant communities, plant species, rare and endemic species, and to the evaluation of the impact of the project on the local flora.

The database of plants in the reservoir region was established based on field investigations. The Three Gorges plant database includes the species' Chinese name, Latin name, family, distribution, geographic distribution, elevation, geographic component, habitat, utilization purpose and reference. Index analysis was carried out by different aims. By screening plants distributed below $200 \mathrm{~m}$ elevatiion. species that would suffer from flooding could be identified. The field work data were used for the analysis of the 
response of the vegetation to the dam construction. Seventeen transects were laid out along the river side from western end, Baxian to eastern end, Yichang. The width of each transect was $10 \mathrm{~m}$, vertical to river flow direction up to $200 \mathrm{~m}$. $10 \times 10 \mathrm{~m}$ quadrat was used as a unit for measuring height. $\mathrm{DBH}$ and canopy relative coverage of plant species.

\section{Results}

\section{1 Species diversity}

Established plant species database provides a full account of 190 families, 1012 genera, 3021 species (29 sub-species, 286 varieties and 16 forms) of known higher plants (except mosses) available in the reservoir region. The total number of the species is $10.28 \%$ of the entire plant species, or $9.85 \%$ of the seed plants in China (Table 1).

Table 1 Flora of the Three Gorges Reservoir region.

\begin{tabular}{lcccccc}
\hline & Family & Genus & Species & Subspecies & Variety & Form \\
Pteridophyta & 26 & 51 & 115 & & 5 & 2 \\
Gymnospermae & 9 & 25 & 42 & & 6 & \\
Angiospermae & & & & & & \\
$\quad$ Dicotyledoneae & 138 & 767 & 2081 & 25 & 249 & 14 \\
Monocotyledoneae & 17 & 169 & 443 & 4 & 26 & \\
Total & 190 & 1012 & 2681 & 29 & 286 & 16 \\
\hline
\end{tabular}

Features of species in the reservoir region are: (1) Plants of Compositae, Rosaceae, Gramineae and Liliaceae are dominant, occupying $21.48 \%$ of all plant species. (2) Many relic plants can be found. These relics include Metasequoia glyptotroboides, Liriodendron chinense, Cathaya argyrophylla, Pseudolarix amabilis, Cercidiphyllum japonicum, Cyclocarya paliurus, Davidia involucrata, and Tetracentron sinensis. (3) Components of flora are very complicate. The flora consist of $31.9 \%$ tropical, $26.97 \%$ temperate elements, $40.99 \%$ of species endemic to China, $0.97 \%$ of the species endemic to the Three Gorges region, and some Mediterranean, central Asia and cosmopolitan species. (4) Rich in endemic and endangered species. Three plant families-Bretchneideraceae, Davidiaceae and Eucommiaceae are endemic to China, which are widely distributed in the area. The Three Gorges reservoir region is one of the three centers for endemic plants in China, namely south-Sichuan and west-Hubei center (Ying, 1984). 47 species listed in the Red Data Book of China, including 22 vulnerable species, 20 endangered species and 5 rare species, are identified. The criterion for classification is set according to international standards and also based on individual situation of the listed species (Table 2). A total of 37 endemic species are only found in the reservoir region (Table 3), Adiantum reniforme var. sinensis is listed as an endangered species and an endemic to the reservoir. Great attention should be paid to the conservation of endangered endemic species with respect to the impact of the Three Gorges Project. 
Table 2 Rare, endangered and vulnerable plant species distributed in the Three Gorges Reservoir region.

\begin{tabular}{|c|c|c|c|c|}
\hline Species & Family & $\begin{array}{l}\text { Distribution in Three } \\
\text { Gorges Reservoir region }\end{array}$ & Status & $\begin{array}{l}\text { Elevation } \\
\text { (m) }\end{array}$ \\
\hline 1. Ophioglossum thermale & Ophioglossaceae & Chongqing, Changshou & V & $600 \sim 1200$ \\
\hline $\begin{array}{l}\text { 2. Adiantum reniforme } \\
\text { var. sinensis }\end{array}$ & Adiantaceae & Wanxian. Shizhu & $\mathbf{E}$ & $150 \sim 380$ \\
\hline 3. Alsophila spinulosa & Cyatheaceae & Chongqing & V & $400 \sim 900$ \\
\hline 4. Cephalotaxus oliveri & Cephalotaxaceae & Yichang, Xingshan, Zigui & $\mathrm{V}$ & 1000 \\
\hline 5. Abies chensiensis & Pinaceae & Badong & V & $1300 \sim 2100$ \\
\hline 6. Cathaya argyrophylla & Pinaceae & Wulong & $\mathbf{R}$ & 900 \\
\hline 7. Picea brachytyla & Pinaceae & $\begin{array}{l}\text { Badong, Xingshan, } \\
\text { Zigui, Wushan }\end{array}$ & V & $1400 \sim 2000$ \\
\hline 8. Picea neobeitchii & Pinaceae & Badong, Xingshan & $\mathrm{E}$ & $1500 \sim 2000$ \\
\hline 9. Pseudolarix kaempferi & Pinaceae & Wanxian & $\mathbf{R}$ & 1000 \\
\hline 10. Pseudotsuga sinensis & Pinaceae & Wanxian, Fengjie & $\mathbf{V}$ & $900 \sim 1200$ \\
\hline 11. Amentotaxus argotaenia & Taxaceae & Xingshan, Wuxi, Shizhu & V & $700 \sim 1200$ \\
\hline $\begin{array}{l}\text { 12. Metasequoia } \\
\text { gluptostroboides }\end{array}$ & Taxodiaceae & Shizhu & $\mathbf{R}$ & $1000 \sim 1200$ \\
\hline 13. Dipteronia sinensis & Aceraceae & $\begin{array}{l}\text { Badong, Yichang. Xing- } \\
\text { shan, Wushan, Wuxi }\end{array}$ & $\mathbf{R}$ & $800 \sim 1900$ \\
\hline 14. Dysosma versipellis & Berberidaceae & $\begin{array}{l}\text { Badong, Yichan, Xing- } \\
\text { shan, Wushan, Wuxi }\end{array}$ & $\mathrm{V}$ & $500 \sim 2100$ \\
\hline 15. Corylus chinensis & Betulaceae & $\begin{array}{l}\text { Zigui, Wulong } \\
\text { Badong, Yichang, Xing- } \\
\text { shan, Wulong }\end{array}$ & V & $900 \sim 2200$ \\
\hline 16. Bretschneidera sinensis & Bretschneideraceae & Chongqing & $\mathbf{R}$ & $500 \sim 1000$ \\
\hline 17. Heptacodium miconioides. & Caprifoliaceae & Xingshan & V & $600 \sim 1000$ \\
\hline $\begin{array}{l}\text { 18. Cercidiphyllum } \\
\text { japonicum. }\end{array}$ & Cercidiphyllaceae & $\begin{array}{l}\text { Badong, Yichang, } \\
\text { Xingshan, Wuxi }\end{array}$ & $\mathbf{R}$ & $1000 \sim 1900$ \\
\hline 19. Eucommia ulmoides. & Eucommiaceae & $\begin{array}{l}\text { eastern Sichuan, } \\
\text { western Hubei }\end{array}$ & $\mathbf{R}$ & $700 \sim 1400$ \\
\hline 20. Juglans regia. & Juglandaceae & $\begin{array}{l}\text { Badong, Yichang, } \\
\text { Wushan, Zigui }\end{array}$ & V & $1400 \sim 1700$ \\
\hline 21. Phoebe bournei & Lauraceae & Xingshan & V & $400 \sim 1000$ \\
\hline 22. Phoebe zhennan & Lauraceae & Yichang, Xingshan, Zigui & V & $400 \sim 1000$ \\
\hline 23. Glycine soja & Leguminosae & Xingshan & V & $300 \sim 1300$ \\
\hline 24. Ormosia hosiei & Leguminosae & Chongqing. Yichang & $\mathrm{V}$ & $350 \sim 900$ \\
\hline 25. Liriodendron chinense & Magnoliaceae & Badong, Wanxian & $\mathbf{R}$ & $650 \sim 1000$ \\
\hline 26. Magnolia officinalis & Magnoliaceae & $\begin{array}{l}\text { Badong, Yichang, } \\
\text { Xingshan, Zigui }\end{array}$ & $\mathbf{E}$ & $300 \sim 1700$ \\
\hline 27. Euryocrymbus cavaleriei & Sapindaceae & Xingshan & $\mathbf{R}$ & $800 \sim 1000$ \\
\hline 28. Sinowilsonia henryi & Hamamelidaceae & Fengdu, Wanxian, Shizhu & $\mathbf{R}$ & $1100 \sim 1350$ \\
\hline 29. Manglietia patungensis & Magnoliaceae & Badong & $\mathbf{E}$ & $700 \sim 1000$ \\
\hline 30. Tetracentron sinensis & Magnoliaceae & $\begin{array}{l}\text { Badong, Yichang. } \\
\text { Xingshan }\end{array}$ & $\mathbf{R}$ & $1100 \sim 2000$ \\
\hline 31. Davidia involucrata & Nyssaceae & $\begin{array}{l}\text { Badong, Xingshan, } \\
\text { Wushan, Wuxi }\end{array}$ & $\mathbf{R}$ & $1000 \sim 1600$ \\
\hline $\begin{array}{c}\text { 32. Dabidia involucrata } \\
\text { var. vilmoriniana }\end{array}$ & Nyssaceae & $\begin{array}{l}\text { Badong, Yichang, } \\
\text { Xingshan, Wushan }\end{array}$ & $\mathbf{R}$ & $1400 \sim 1900$ \\
\hline
\end{tabular}


(Continued)

\begin{tabular}{|c|c|c|c|c|}
\hline 33. Coptis chinensis & Ranunculaceae & $\begin{array}{l}\text { eastern Sichuan, } \\
\text { Western Hubei }\end{array}$ & $\mathbf{R}$ & $1000 \sim 2000$ \\
\hline 34. Berchemiella wilsonii & Rhamnaceae & Xingshan & $\mathbf{E}$ & $900 \sim 1200$ \\
\hline 35. Emmenopterys henryi & Rubiaceae & $\begin{array}{l}\text { Badong, Yichang, Xing- } \\
\text { shan, Wushan, Wanxian }\end{array}$ & $\mathbf{R}$ & $600 \sim 1400$ \\
\hline 36. Tapiscia sinensis & Staphyleaceae & $\begin{array}{l}\text { Badong, Yichang, } \\
\text { Xingshan, Fengjie, } \\
\text { Wanxian, Shizhu }\end{array}$ & $\mathbf{R}$ & $600 \sim 1400$ \\
\hline 37. Pterostyrax psilophylla & Styraceae & $\begin{array}{l}\text { Badong, Yichang. } \\
\text { Xingshan }\end{array}$ & V & $1000 \sim 1800$ \\
\hline 38. Camellia grijsii & Theaceae & Yichang & $\mathrm{V}$ & $150 \sim 500$ \\
\hline 39. Stewartia sinensis & Theaceae & $\begin{array}{l}\text { Badong, Yichang, } \\
\text { Xingshan, Wushan }\end{array}$ & V & $900 \sim 1900$ \\
\hline 40. Euptelea pleiospernum & Trochodendraceae & $\begin{array}{l}\text { Badong, Yichang, } \\
\text { Xingshan, Wanxian, } \\
\text { Fengjie, Wushan }\end{array}$ & $\mathbf{R}$ & $700 \sim 1800$ \\
\hline 41. Pteroceltis tatarinowii & Ulmaceae & Badong, Xingshan, Zhigui & $\mathbf{R}$ & $500 \sim 800$ \\
\hline 42. Trillium tschonoskii & Liliaceae & $\begin{array}{l}\text { Badong. Wushan, } \\
\text { Wuxi, Wanxian }\end{array}$ & $\mathbf{V}^{\prime}$ & $800 \sim 2200$ \\
\hline 43. Changnienia amoena & Orchidaceae & $\begin{array}{l}\text { Wushan, Wanxian. } \\
\text { Zhongxian. Shizhu }\end{array}$ & $\mathbf{R}$ & $740 \sim 1300$ \\
\hline 44. Gastrodia elata & Orchidaceae & $\begin{array}{l}\text { eastern Sichuan. } \\
\text { Western Hubei }\end{array}$ & $\mathrm{V}$ & $1200 \sim 2150$ \\
\hline 45. Ginkgo biloba & Ginkgoaceae & Cultivated & $\mathbf{R}$ & $300 \sim 1100$ \\
\hline 46. Dimocarpus longan & Sapindaceae & Cultivated & V & $70 \sim 900$ \\
\hline 47. Litchi chinensis & Sapindaceae & Cultivated & $\mathrm{V}$ & $70 \sim 800$ \\
\hline
\end{tabular}

Table 3 Plant species endemic to the Three Gorges Reservoir region.

\begin{tabular}{lllr}
\hline Species & Family & Distribution & Elevation (m) \\
\hline 1. Adianthum remiforme var. sinense & Adiantaceae & Wanxian, Shizhu & $80 \sim 430$ \\
2. Plagiogyria caudifolia & Plagiogyriaceae & Chongqing & 800 \\
3. Tsuga chinense var. robusta & Pinaceae & Badong & 1800 \\
4. Salix michtotricha & Salicaceae & Xingshan & $900 \sim 1700$ \\
5. Salix polyclona & Salicaceae & Xingshan, Badong & $2100 \sim 2600$ \\
6. Pilea rubriflora & Urticaceae & Yichang & 1210 \\
7. Stellaria henryi & Caryophyllaceae & Badong & 1020 \\
8. Berberis julianae var. batungensis & Berberidaceae & Badong & $1200 \sim 1800$ \\
9. Mahonia confusa var. bournei & Berberidaceae & Yichang & \\
10. Neolitsea aurata var. glauca & Lauraceae & Fengjie & $800 \sim 850$ \\
11. Sedum wilsonii & Crassulaceae & Xingshan & $:$ \\
12. Potentilla fulgens var. acutiserrata & Rosaceae & Fengjie & \\
13. Potentilla pendula & Rosaceae & Fengjie & 2600 \\
14. Padus brachypoda var. microdonta & Rosaceae & Zhigui & $840 \sim 2600$ \\
15. Rubus wushanensis & Rosaceae & Wushan & 2000 \\
16. Stizolobium brunnescens & Leguminosae & Badong \\
17. Flueggea leucopyrus & Euphorbiaceae & Badong & \\
18. Leptopus chinensis var. pubescens & Euphorbiaceae & Yichang, Xingshan & $300 \sim 900$ \\
19. Securinega wuxiensis & Euphorbiaceae & Wushan, Wuxi & $60 \sim 250$ \\
20. Myricaria laxiflora & Aquifoliaceae & Badong, Zhigui, & $70 \sim 150$ \\
21. Ilex jinyunensis & Wushan & 750
\end{tabular}


(Continued)

22. Celastrus orbiculatus var. cunneatus

\begin{tabular}{llc} 
Celastraceae & Yichang & 600 \\
Sabiaceae & Wuxi & 1000 \\
Buxaceae & Badong & 2100 \\
Aceraceae & Yichang & $750 \sim 1200$ \\
Rhamnaceae & Zhigui & $700 \sim 1500$ \\
Actinidiaceae & Badong, Wuxi & $2300 \sim 2400$ \\
Umbelliferae & Wuxi & $1000 \sim 1300$ \\
Umbelliferae & Badong & 1200 \\
Scrophulariaceae & Xingshan & \\
Scrophulariaceae & Badong & $370 \sim 1000$ \\
Gesneriaceae & Kaixian & 900 \\
Gesneriaceae & Wuxi & $600 \sim 1600$ \\
Gesneriaceae & Shizhu & $800 \sim 1500$ \\
Caprifoliaceae & Badong, Xingshan, & 185 \\
& Wushan & $950 \sim 1600$ \\
\hline Gramineae & Wushan & \\
Liliaceae & Badong & \\
\hline
\end{tabular}

23. Meliosma subverticillaris

24. Buxus sinica var. pumila

25. Acer oblongum var. trilobum

26. Rhamnus tzekweiensis

27. Actinidia tetramera var. badongensis

28. Ligusticum wuxiense

29. Hydrocotyle dielsiana

30. Orthocarpus chinensis

31. Pedicularis conifora

32. Chirita fangii

33. Deinocheilos sichuanense

34. Isometrum villosum

35. Lonicera mucronata

36. Neyraudia wushanica

37. Smilax riparia var. pubescens

Liliaceae

\section{2 Vegetation diversity}

The reservoir lies in the North of mid-subtropical zone. The evergreen forests dominated by Castanopsis and Phoebe are zonal vegetation (Wu, 1980). The percent of forest coverage has been reduced to only $19.5 \%$ because of severe impact of human activities. Forests that have been rarely disturbed by human activities are only found at the upper parts of the mountains and only account for $30 \%$ of the total forested area. Manmade or semi-natural forests such as Pinus massoniana and Cupressus funebris types are widely distributed in the region, possessing about $60 \%$ of total forested area $(40 \%$ scattered young forests). Small remnant patches of the original vegetation are only seen in the northeastern and southeastern wolds. In lowland, evergreen forests cover $0.01 \%$ of total reservoir area.

The main vegetation types, except for original agriculture fields, form 89 formations. The coniferous forest area is the biggest. Pinus mossoniana and Cupressus funebris forests, which are mostly artificially planted, are widely distributed in the terrace areas that are under $1000 \mathrm{~m}$ elevation, and are composed of acid and calcareous soil. Pinus henryi and $P$. armandii forests are distributed on the middle and upper parts of the mountains. Picea neoveitchii and Abies fargesii forests can be found on the submountain or upper-mid mountain. There are some distributions of Cunninghamia lanceolata forest. Moreover, some patchy areas of Keteleeria davidiana, Metasequoia glyptostroboides and Cathaya argyrophylla forests are present. The remained types of evergreen broadleaved forest are mainly composed of Castanopsis, Cyclobalanopsis glauca and Quercus engleriana. Machilus and Phobe forests are distributed in some areas. The Castanposis forests mainly include Castanopsis fargesii, C. eyrei, C. sclerphylla types. Forests of Quercus spinosa, $Q$. spathulata are present in the middle part of the mountain. The dominant species of broad-leaved deciduous forests mainly include Quercus, Castanea, Betula, Populus generas. The main types are of Quercus serrata var. brevipetilata, Q. aliena var. acuteserrata, $Q$. actutissina. $Q$. variabilis, Castanea sepuinii, C. henryii, Betula utilis, B. albosinesis, B. luminifera; Populus davidiana forests. There are some 
forests of Alnus cremastogyne, Platycarya strobibocea, Fagus as well. The understories of deciduous broad-leaved forests sometimes own saplings of evergreen trees or evergreen shrubs.

Conifer and broad-leaved mixed forests mainly are Pinus massoniana and Quercus variabilis; Cupressus funebris and Quercus variabilis etc. There are some distribution of bamboo forests in the reservoir region, mainly Phyllostachys pubescences, Ph. nigra var. hennis, Sinocalamus affinis and shrub types of Phyllostachy congesta and Sinarnndinaria nitida etc.

Shrubland is an important type of vegetation, and covers $20 \%$ of the total reservoir region. The main types of shrubland are Distyeium chinense. Buxus sinica var. pumila and Rhododendron simsii, Sageretia thea, Myrsine africana, Pyracantha fortuneana, Cotinus coggygria, Loropetalum chinense, Vitex negunda, Rosa cymosa shrub.

Grassland covers $15 \%$ of the total reservoir area. Main grass types are Pogonatherum crinitum. Heteropohom comtortus, Imperata cylindrica var. major, Eulaliopsis binata, Arthraxon hispidus, Arundinella hirta communities.

Vertical distribution of the vegetation in the reservoir region is not distinct due to serious impact by human activities. The analysis of remained natural vegetation demonstrates that belts of broadleaf evergreen forests, evergreen deciduous broad-leaved mixed forests, mountain conifer and broad-leaved forests and sub-mountain conifer forest are at the elevations under $1300 \mathrm{~m}, 1300 \sim 2200 \mathrm{~m}$ and above $2200 \mathrm{~m}$ respectively. This vertical distribution is only well maintained on the southern slope of Shenglongia mountain range in the northeastern part of the reservoir region.

4. 3 Impact of Three Gorges Hydroelectric Project on plant biodiversity

4.3. 1 Effect of flooding on plant species diversity

Based on results obtained by screening plants distributed under $200 \mathrm{~m}$ elevation in the database, the flooding caused by the dam will have severe impact on the plants of 120 families, 358 genera and 550 species. In terms of the absolute quantity of the species, families of Gramineae, Compositae. Euphorbiaceae and Rosaceae will be the most affected. In terms of the severity of the impact, Sapindaceae, Distylium of Hamamelidaceae, Hibiscus of Malvaceae, Myricaria of Tamaricaceae, Bauhinia of Leguminosae, Securinega of Euphorbiaceae and Neyraudia of Gramineae will be most greatly affected. Plants distributed in the reservoir area and listed in "Red Data Book of China" are surveyed clearly for their distribution under $200 \mathrm{~m}$. The main distribution zone of $A-$ diantum reniforme var. sinensis will be severely damaged and other species will not. Since the distribution of this species is not limited to the areas under $200 \mathrm{~m}$, therefore, if the original place above $200 \mathrm{~m}$ is protected, flooding would not directly destroy this species totally. Off-site protection of Adiantum reniforme var. sinensis has been successfully done by the Wuhan Institute of Botany and also a successful bacteria-free cultivation has been completed by the Institute of Botany of CAS, all these have laid a good foundation for the germplasm resource conservation.

Endangered and rare species like Ginkgo biloba, Dimocarpus longan, Litchi chinensis have been introduced to the reservoir region historically. Species of high economic values like Dimocarpus longan and Litchi will be endangered severely by flooding. Among the 37 species endemic to the reservoir region, Neyrara washanica and Myricaria laxiflora will be severely affected by flooding. They will disappear unless off-site protection

- 70 . 
measures are taken.

\subsubsection{Effect of flooding on community}

There will be 27 plant communities to be affected by flooding according to the survey results of 17 transects laid out under $200 \mathrm{~m}$ elevation (Fig. 2). Buxus sinica var. pumila shrub. Securinega wuxiensis shrub and Myricaria laxiflora shrub will be flooded totally, while other types will be found from similar habitats. Economic loss of vegetation by flooding will be inestimable.



Fig. 2 Plant community types under $200 \mathrm{~m}$ elevation, which will be flooded when the reservoir region be filled with water.

1. Pinus massoniana forest; 2. Cupressus funebris forest; 3. Robinia pseudoacacia forest; 4. Eucalyptus forest; 5 . Citrus forest: 6. Sinocalamus affiuis forest; 7. Bamboo forest; 8. bamboo shrubs; 9. Distylium chinesis shrub: 10. Vitex negunda shrub: 11. Vitex negunda, Cotinus coggygria shrub: 12. Cotinus cogygria shrub; 13. Coriaria nepalensis shrub; 14. Indigofera ichangensis shrub; 15. Ficus tikoua shrub; 16. Rosa cymosa shrub: 17. Quercus aliena shrub: 18. Cyperus rotundus grassland: 19. Imperata cylindria grassland: 20. Heteropogon contortus grassland: 21. Arundinella hirta grassland: 22. Arthraxon hispidus grassland; 23. Phragmites australis grassland: 24. Miscanthus sacchariflorus grassland; 25. Miscanthus sinensis grassland: 26. Saccharum arundinaceum grassland; 27. Agriculture field.

4.4 Strategies for protection of plant biodiversity in the reservoir region

The original habitats of some species will be flooded after the reservoir is filled with water. Flooding will have severe impact on rare and endangered plants, and will directly lead to the disappearance of 3 species and 3 community types unless protection strategies are to be taken. Cares must be taken for Adiantum reniforme var. sinensis conservation. Disappearance of forests, shrublands and grasslands by flooding will lead to economic and ecological losses. Therefore, in order to minimize these influences, it is imperative that the protective forest systems have to be strengthened during the exploitation migration, otherwise. new waves of migration will again damage species, vegetation and environment in the region. Strengthening nature reserve protections and the research on the restoration of degraded ecosystems and optimized artificial ecosystems will serve for economic development. Along with bulding the Three Gorges dam, botanical gardens to keep rare and endangered plant species will help the off-site protection of them. 


\section{ACKNOWLEDGMENTS}

This research project was financially supported through grant of 75-16-06 of State Science and Technology Commission of China. We are much indebted to Professor Jin Yixing, Mr. Jiang Mingxi and Mr. Zhang Quanfa of Wuhan Institute of Botany, Chinese Academy of Sciences and Professor Hu Dong of Capital Normal University for taking part in the field expedition, to Dr. Han Xingguo for providing valuble criticism of the draft and checking the English text.

\section{REFERENCES}

Bretschneider E, 1962. History of European botanical discoveries in China. London

Caufield C. 1993. The Yangtze beckons the Yankee dollar. New Scientist, 108 (1485): 26 27

Chen Guojie (ed.). 1993. The impact of the Three Gorges hydroelectric project on ecological environment. Science Press. Beijing (in Chinese)

Chen Lingzhi (ed.). 1993. Chinese Biodiversity-current status and preserving strategies. Science Press, Beijing (in Chinese)

Fu Liguo, Jin Jianming (eds. ). 1992. Plant red-data book of China. Science Press, Beijing

Jin Yixing. Chen Zhuoliang. Zheng Zhong. Xu Tianquan. 1983. A study on the relationship of vegetation types and soil erosion in the Three Gorges region, West of Hubei Province, Wuhan Botanical Research, 1 (2): 189 198 (in Chinese)

Jin Yixing, Chen Zhouliang, Zheng Zhong, Xu Tianquan, 1984. A report on the expedition of vegetation and environment in Changjiang. Sanxia (Gorge of Yangtze River) reservoir region, Wuhan Botanical Research, 2 (supplement), 1 100 (in Chinese)

Wu Zhenyi (ed.), 1980. Vegetation of China. Science Press, Beijing (in Chinese)

Ying Junsheng, Zhang Zhishong, 1984. Endemism in the flora of China-studies on the endemic genera. Acta Phytotaxonnomica Sinica, $22(4): 259 \sim 268$ (in Chinese)

Zheng Zhong, 1984. The characteristics of the flora and an outline of the distribution of plants in Hubei Province. China. Wuhan Botanical Research, $2(1): 165 \sim 188$ (in Chinese) 